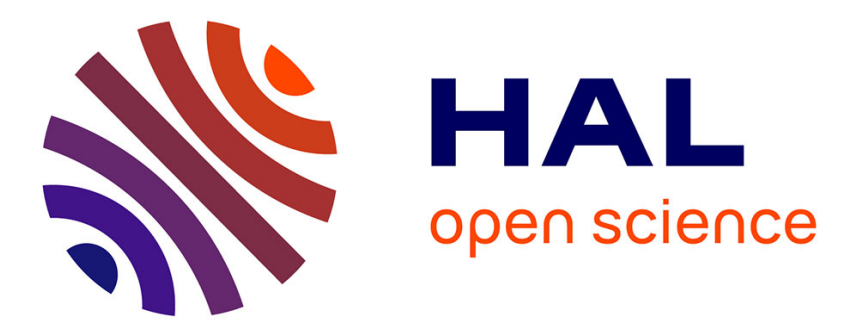

\title{
Large-scale hydrogen release in an isothermal confined area
}

Jean-Marc Lacome, Yves Dagba, Lionel Perrette, Didier Jamois, Christophe Proust

\section{- To cite this version:}

Jean-Marc Lacome, Yves Dagba, Lionel Perrette, Didier Jamois, Christophe Proust. Large-scale hydrogen release in an isothermal confined area. 2. International Conference on hydrogen safety (ICHS 2007), Sep 2007, San Sebastian, Spain. pp.7. ineris-00973269

HAL Id: ineris-00973269

https://hal-ineris.archives-ouvertes.fr/ineris-00973269

Submitted on 4 Apr 2014

HAL is a multi-disciplinary open access archive for the deposit and dissemination of scientific research documents, whether they are published or not. The documents may come from teaching and research institutions in France or abroad, or from public or private research centers.
L'archive ouverte pluridisciplinaire HAL, est destinée au dépôt et à la diffusion de documents scientifiques de niveau recherche, publiés ou non, émanant des établissements d'enseignement et de recherche français ou étrangers, des laboratoires publics ou privés. 


\title{
LARGE-SCALE HYDROGEN RELEASE IN AN ISOTHERMAL CONFINED AREA
}

\author{
J.M. LACOME ${ }^{1}$, Y. DAGBA, D. JAMOIS ${ }^{2}$, L. PERRETTE ${ }^{1}$, CH. PROUST $^{3}$ \\ ${ }^{1}$ Process Safety Engineers at "Institut National de l'Environnement Industriel et des RISques \\ (INERIS)", 60550 Verneuil-en-Halatte, France, Jean-Marc.Lacome@ ineris.fr \\ ${ }^{2}$ Test Engineer at "Institut National de l'Environnement Industriel et des RISques", 60550 \\ Verneuil-en-Halatte, France, Didier.Jamois@ineris.fr \\ ${ }^{3}$ Senior Scientist at "Institut National de l'Environnement Industriel et des RISques (INERIS)", \\ 60550 Verneuil-en-Halatte, France), Christophe.Proust@ineris.fr
}

\begin{abstract}
INERIS has set up large-scale fully instrumented experiments to study the formation of flammable clouds resulting from a finite duration spillage of hydrogen in a quiescent room $\left(80 \mathrm{~m}^{3}\right.$ chamber). Concentration, temperature and mass flow measurements were monitored during the release period and several hours after. Experiments were carried out for mass flow rates ranging from $0,2 \mathrm{~g} / \mathrm{s}$ to $1 \mathrm{~g} / \mathrm{s}$. The instrumentation allowed the observation and quantification of rich hydrogen layers stratification effects. This paper presents both the experimental facility and the test results. These experimental results can be used to assess and benchmark CFD tools capabilities.
\end{abstract}

\section{INTRODUCTION}

In a medium term future, one could expect an increasing number of hydrogen energy systems to be operated or stored (mobile applications) inside buildings (dwellings, garages,...). Whereas outside location would be preferable in most cases to prevent leaking hydrogen from accumulating, inside location will remain in many cases a necessity although moderate releases of hydrogen in confined or semi-confined geometry may present a serious risk since combustible mixtures may form. Literature is rather poor on that critical subject [1] to allow for a robust analysis and predictive quantification model or safety standard development. In order to better understand how hydrogen behaves when released in confined space and especially to assess in which circumstances explosive mixtures may form, INERIS has set up large-scale fully instrumented experiments to study the mechanisms of the formation of flammable clouds resulting from a finite duration spillage in a quiescent room. Concentration, temperature and mass flow measurements were monitored during the release period and several hours after in order to investigate the diffusion process. The objective of this paper is to provide consistent experimental results on hydrogen release in large-scale closed and quiescent volume for realistic leakage. These results will help to better understand and assess small hydrogen release in closed area and therefore contribute to a better risk assessment and control.

\section{TEST FACILITY DESCRIPTION}

\subsection{Chamber}

The experiments were performed in a $80 \mathrm{~m}^{3}$ chamber which is built inside a rock gallery (Figure 1). This chamber has the shape of a rectangular box, see Figure 2, with average dimensions $7.2 \times 3.78$ x $2.88 \mathrm{~m}$ in length, width and height respectively. The garage ceiling and the front side are made up of a wood and plastic sheeting, whereas the ground has a negligible slope in the length and width directions. The rock solid mass ensures a thermal stability of the inner and prevents any convection effect.

The walls are closed and tight except the front side that accommodates 3 holes (Figure 2). The bigger one, which is referred to as "opening 1" in the Figure 2, has a diameter of $0.15 \mathrm{~m}$ and is located at the 
top. Its goal is to ventilate the chamber between the experiments (safety reasons). There are two other smaller opening, named as "openings $2 \& 3$ " in the Figure 2. They are $0.05 \mathrm{~m}$ in diameter and were used to pass on the electrical cables. These holes were kept closed unless otherwise specified, during all the experiments.

The left, right and bottom sides are not smooth surfaces; the roughness size on those surfaces is between $5 \mathrm{~mm}$ and $10 \mathrm{~mm}$ (Figure 3).

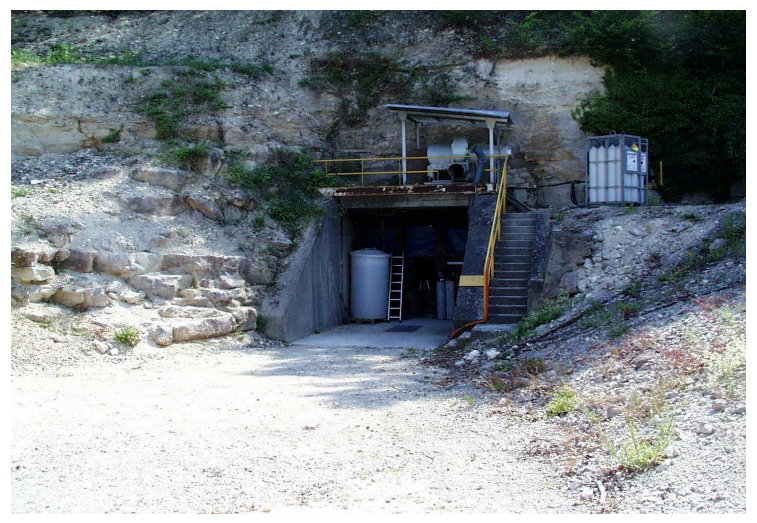

Figure 1: General view of the experimental set up environment

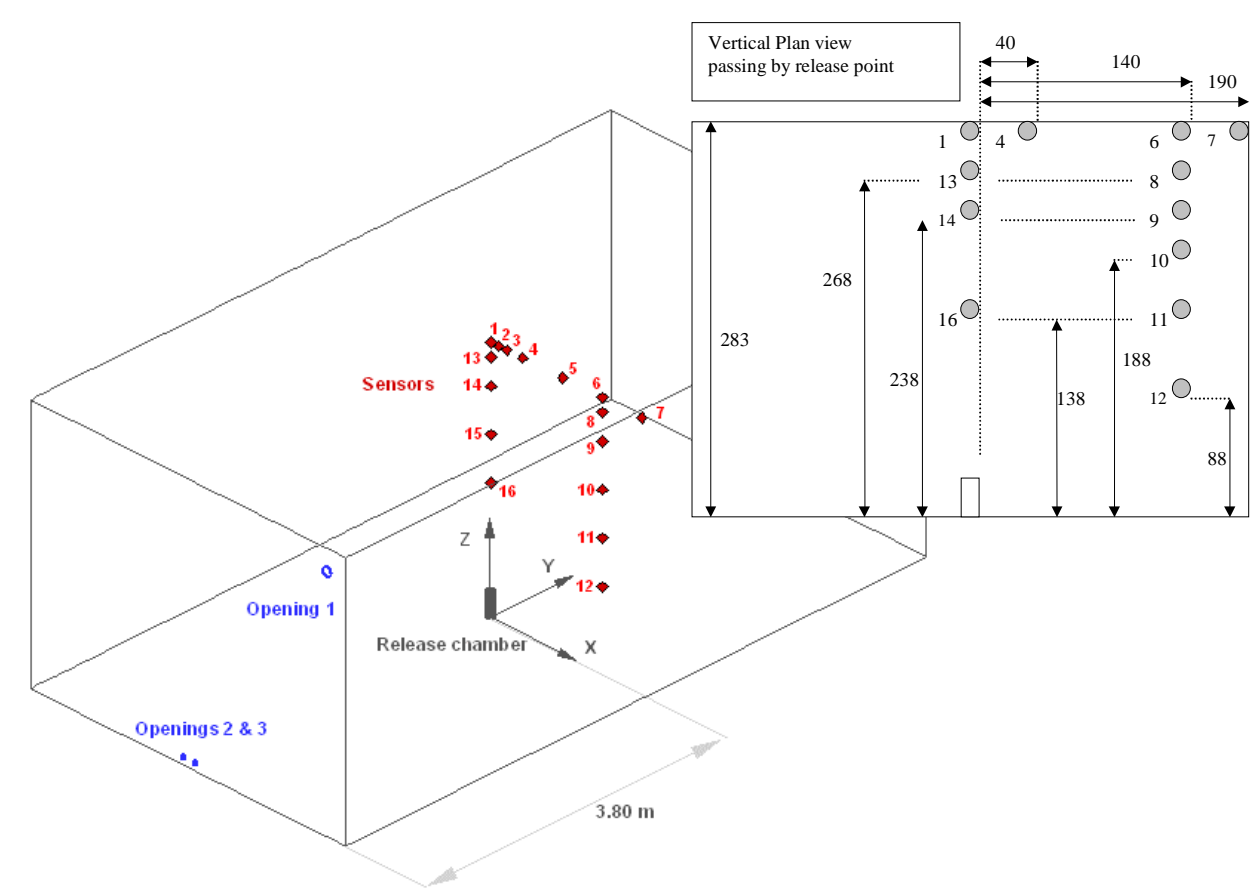

Figure 2 : Release chamber scheme and sensor positions (dimensions in $\mathrm{cm}$ ) 


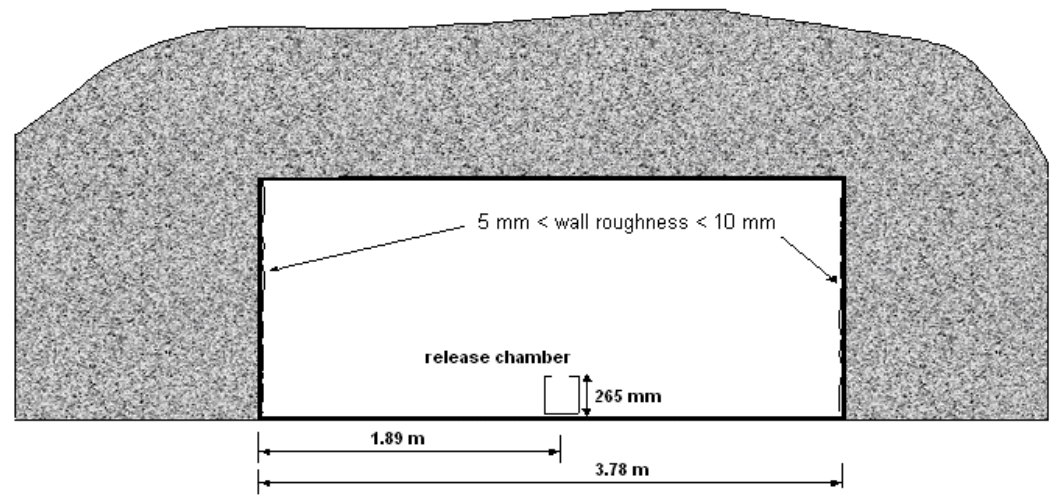

Figure 3 : Injector location in the $\mathrm{x}$-direction (see Figure 2 for the reference frame)

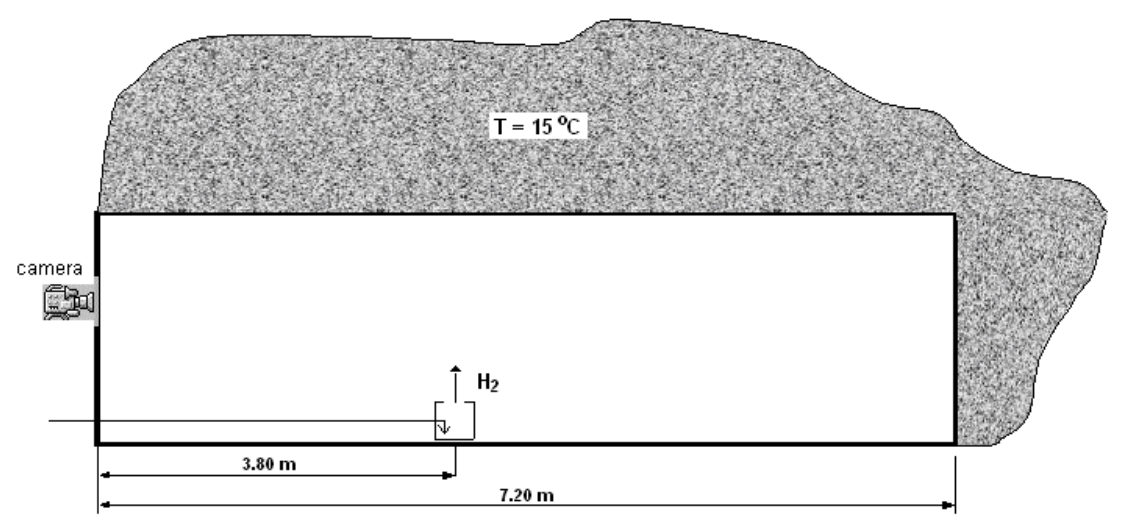

Figure $4:$ Injector location in the y-direction

\subsection{Release apparatus and position}

Hydrogen was released through an orifice on top of a stabilisation chamber as shown in Figure 5. Homogenization of the flow was obtained using a dispersion bed. The internal diameter of the release chamber was $120 \mathrm{~mm}$ and its height $265 \mathrm{~mm}$. The hydrogen flow was seeded with nanometric ammonium chloride droplets to allow for flow and stratification visualisation by means of an argon laser.

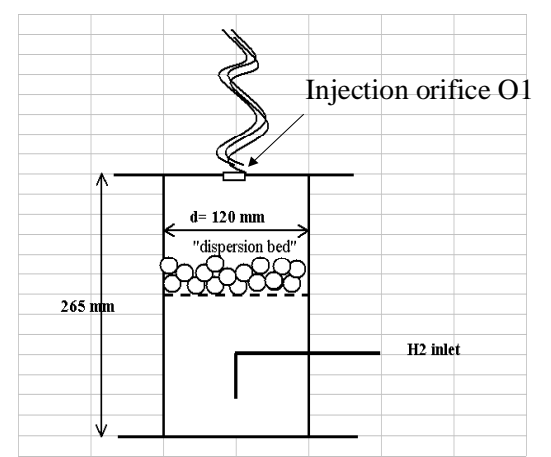

Figure 5 : Hydrogen injector 
Upstream of the release apparatus was connected a home-made hydrogen mass-flow controller. Figure 3 and Figure 4 show the injector location inside the test chamber.

For a given mass flow rate, it was possible with the hydrogen injector to vary the speed of the hydrogen jet by changing the diameter of the top opening (O1 in Figure 5). The mean velocity is then given by the following equation:

$U=(m * V o l) /(C d * M * S)$

where $\mathrm{m}$ - mass flow rate, $\mathrm{g} / \mathrm{s} ; \mathrm{Vol}$ - molar volume, $\mathrm{m}^{3} / \mathrm{mol} ; C d$ - discharge coefficient, -; $\mathrm{M}$ - molar weight, $\mathrm{g} / \mathrm{mol} ; \mathrm{S}$ - orifice area, $\mathrm{m}^{2}$.

We first had to evaluate the discharge coefficient, which could vary from 0.62 to 0.7 for sonic velocity. During previous tests with hydrogen and helium, a value of 0.68 for $\mathrm{Cd}$ gave good agreement between gas velocity using equation 1 and measured value. Measurements of the pressure difference between the interior of the release apparatus and the outside also allow the quantification of the flow mean velocity.

\subsection{Mass flow control}

The hydrogen mass flow rate is controlled by a home-made system based on the shocked flow principle. Above a given upstream pressure, the exit velocity at the orifice is constant and equal to the speed of sound of the leaking gas (sonic release). Under these conditions, and for a given orifice, the desired mass flow rate can be obtained by adjusting the upstream pressure by means of the gate valves V1 \& V2 in Figure 6. Correlation between upstream pressure and desired mass flow rate requires calibration to take place before the operation. For the purpose of calibration, (see Figure 6), the mass flow control set up (left tank up to sonic nozzle) is associated to the calibration apparatus (right hand side equipment after sonic nozzle).

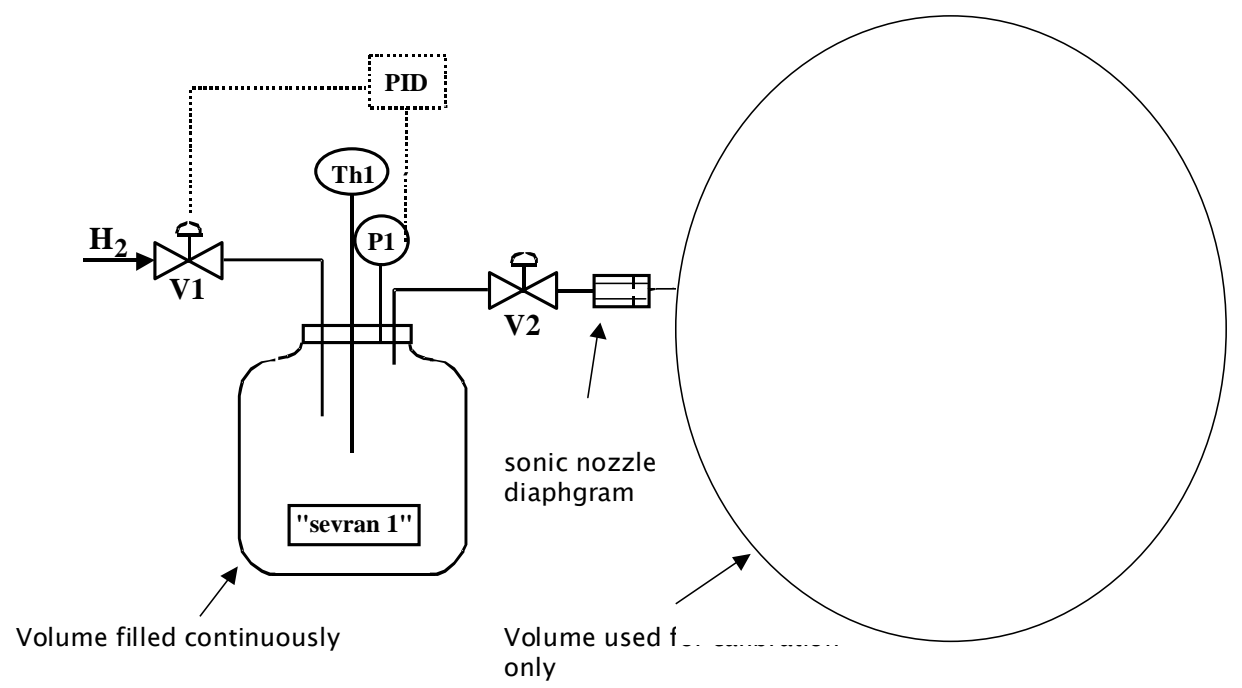

Figure 6: mass flow rate measurement

Sonic openings with different diameters generated hydrogen flow rates between $5 \mathrm{mg} / \mathrm{s}$ and $10 \mathrm{~g} / \mathrm{s}$.

\subsection{Concentration measurements}

Three paramagnetic analysers were used to carry out measurements of concentration in the chamber. An automatic switch allowed to connect four points of measurement to each one of these analysers, see Figure 7. 


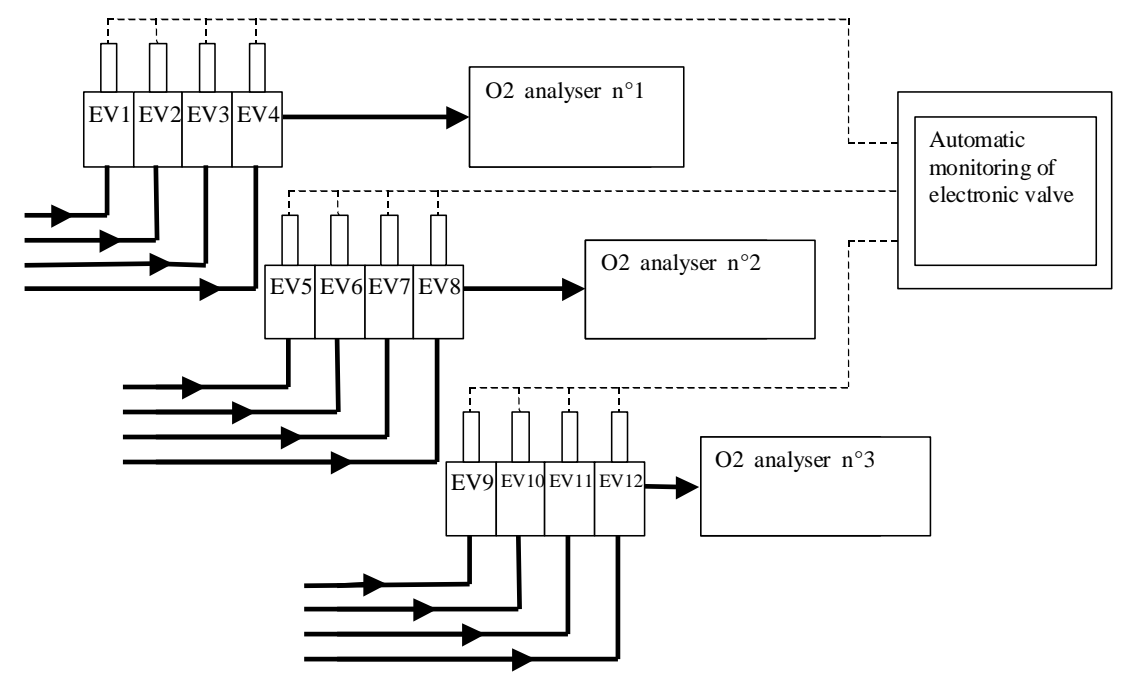

Figure 7 : diagram of the automatic sampling device in 12 points of the chamber facility

Given the response time of the devices and the filling times of the sampling lines, the measurement time for each sampling point was $80 \mathrm{~s}$. Each analyser provides an uninterrupted and analogical signal which is proportional to concentration of oxygen circulating in the measuring cell. From the ouptut signal is deduced the value corresponding to the concentration of the four points of measurement. Errors on the measurements were estimated to be less than $0,02 \%$ (vol.).

Sixteen sampling points were used to measure the hydrogen concentration in the chamber. They were all located on a x-z plane passing through the centre of the release chamber (as shown in Figure 2). Table 1 lists all the locations of the sampling point and the opening in terms of the $\mathrm{x}, \mathrm{y}$, and $\mathrm{z}$ coordinates.

Table 1 : Sensors and openings location

\begin{tabular}{|c|c|c|c|}
\hline & $\mathrm{X}(\mathrm{cm})$ & $\mathrm{Y}(\mathrm{cm})$ & $\mathrm{Z}(\mathrm{cm})$ \\
\hline Chamber size & 378 & 720 & 288 \\
Source location & 0 & 0 & 0 \\
Opening 1 centre location & 180 & -380 & 273 \\
Opening 2 centre location & 7,5 & -380 & 7,5 \\
Opening 3 centre location & $-7,5$ & -380 & 7,5 \\
Sensor 1 location & 0 & 0 & 283 \\
Sensor 4 location & 40 & 0 & 283 \\
Sensor 5 location & 90 & 0 & 283 \\
Sensor 6 location & 140 & 0 & 283 \\
Sensor 7 location & 190 & 0 & 283 \\
Sensor 8 location & 140 & 0 & 268 \\
Sensor 9 location & 140 & 0 & 238 \\
Sensor 10 location & 140 & 0 & 188 \\
Sensor 11 location & 140 & 0 & 138 \\
Sensor 12 location & 140 & 0 & 88 \\
Sensor 13 location & 0 & 0 & 268 \\
Sensor 14 location & 0 & 0 & 238 \\
Sensor 16 location & 0 & 0 & 138 \\
\hline
\end{tabular}

\subsection{Temperature}

Temperature was measured in the mixing tank (before the injector), at the outlet orifice and at the chamber centre (ambient temperature). This data was used to calibrate the mass flow rate at the injection. 


\subsection{Video recording}

For safety reasons related to the presence of a laser source in the test room, video recording was possible only with helium releases but not with hydrogen. The camera was located at the entrance of the chamber (see Figure 4) and allowed to visualise the flow structure on the same plane as the one where the sensors are positioned. A laser plan was set up in order to improve contrast and to better visualise the turbulence pattern caused by the release.

\subsection{Experimental cases}

Tests were performed with different mass flow rates ranging from $0,2 \mathrm{~g} / \mathrm{s}$ to $1 \mathrm{~g} / \mathrm{s}$ and different orifice diameters from $5 \mathrm{~mm}$ to $20 \mathrm{~mm}$. These release values correspond to realistic industrial environment. The table below summarises the test conditions. It is worth noting that all investigated releases were subsonic.

Table 2 : Test cases for hydrogen releases

\begin{tabular}{|c|c|c|c|c|c|c|c|}
\hline $\begin{array}{c}\text { leaking } \\
\text { gas } \\
\text { temperat } \\
\text { ure }\end{array}$ & $\begin{array}{c}\text { Flow rate } \\
(\mathrm{g} / \mathrm{s})\end{array}$ & $\begin{array}{c}\text { Release } \\
\text { diameter } \\
(\mathrm{mm})\end{array}$ & $\begin{array}{l}\text { Release } \\
\text { direction }\end{array}$ & $\begin{array}{c}\text { Exit } \\
\text { velocit } \\
y(\mathrm{~m} / \mathrm{s})\end{array}$ & $\begin{array}{l}\text { Release } \\
\text { duration } \\
\text { (s) }\end{array}$ & $\begin{array}{l}\text { Opening status } \\
\text { (open/closed) }\end{array}$ & $\begin{array}{l}\text { Observation } \\
\text { Time (s) }\end{array}$ \\
\hline \multirow{6}{*}{$10^{\circ} \mathrm{C}$} & 0,7 & 20 & \multirow{6}{*}{$\overbrace{\substack{0 \\
0}}^{\overline{0}}$} & 38 & 240 & closed & 7200 \\
\hline & 0,7 & 20 & & 38 & 240 & open & 7200 \\
\hline & 1 & 20 & & 53 & 240 & closed & 7200 \\
\hline & 1 & 10 & & 210 & 240 & closed & 7200 \\
\hline & 0,2 & 20 & & 11 & 240 & closed & 7200 \\
\hline & 0,2 & 5 & & 170 & 240 & closed & 7200 \\
\hline
\end{tabular}

Release duration was limited to $240 \mathrm{~s}$ for safety reasons but the observation took longer to investigate the diffusion phenomenon. Test cases were also carried out with helium with similar released mass flow rates. Details are given in table below.

Table 3 : Test cases for helium releases

\begin{tabular}{|c|c|c|c|c|}
\hline $\begin{array}{c}\text { Flow } \\
\text { rate } \\
(\mathrm{g} / \mathrm{s})\end{array}$ & $\begin{array}{c}\text { Release } \\
\text { diameter } \\
(\mathrm{mm})\end{array}$ & $\begin{array}{c}\text { Exit } \\
\text { velocity } \\
(\mathrm{m} / \mathrm{s})\end{array}$ & $\begin{array}{c}\text { Release } \\
\text { duration } \\
(\mathrm{s})\end{array}$ & $\begin{array}{c}\text { Opening } \\
\text { status } \\
(\text { open/closed } \\
)\end{array}$ \\
\hline 1,84 & 20 & 55 & 240 & closed \\
\hline 1,84 & 10 & 215 & 240 & closed \\
\hline 0,4 & 5 & 190 & 240 & closed \\
\hline
\end{tabular}

\section{EXPERIMENTAL RESULTS AND DISCUSSIONS}

\subsection{Convection phase and diffusive phase}

The experimental results show that for all the subsonic jets stratification takes place rapidly at the top. A typical result is given in Figure 8. A diffusion phase, characterised by a long observation time, dissipates this stratification. The concentration in the chamber became homogeneous after four hours for every test case. 


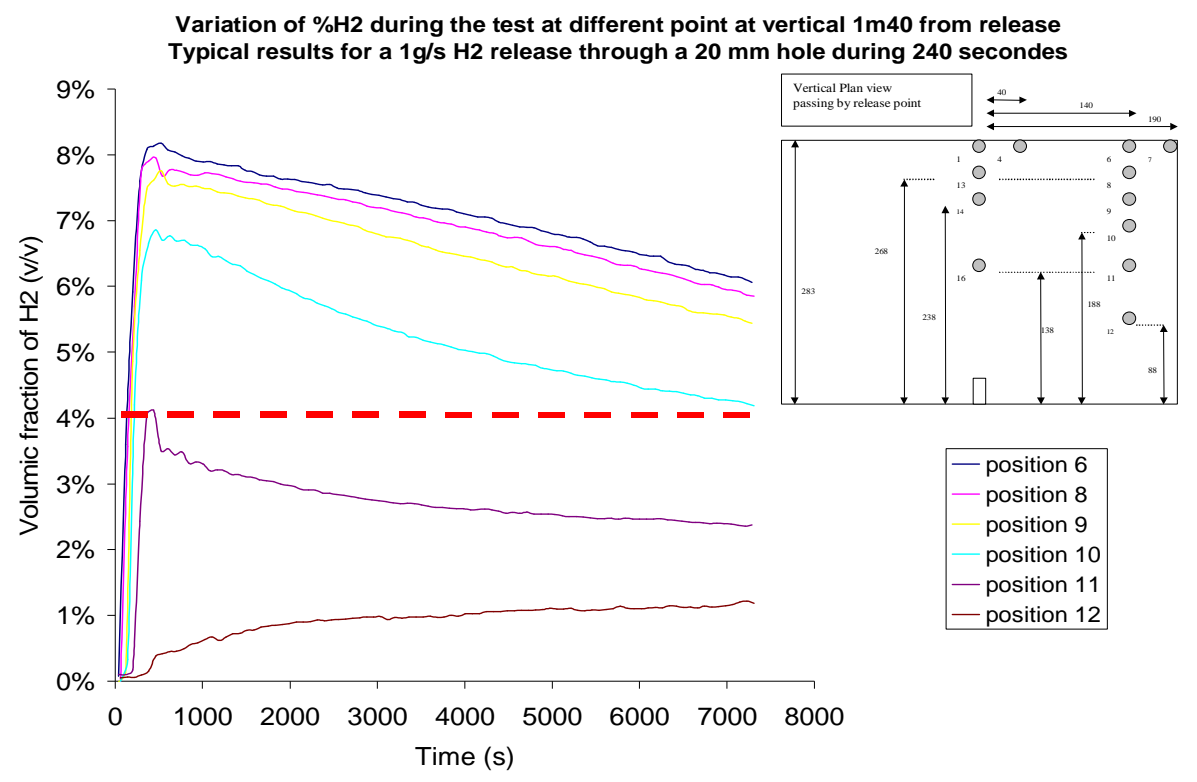

Figure 8: variation of $\% \mathrm{H} 2$ for a $1 \mathrm{~g} / \mathrm{s} \mathrm{H} 2$ release through a $20 \mathrm{~mm}$ hole

For the above case, the $4 \%$ horizontal limit, which corresponds to hydrogen Lower Limit of Inflammability (LFL), is obtained between sensor 10 and 11. In Figure 9, we clearly see a horizontal homogeneous layer of hydrogen close to the ceiling,

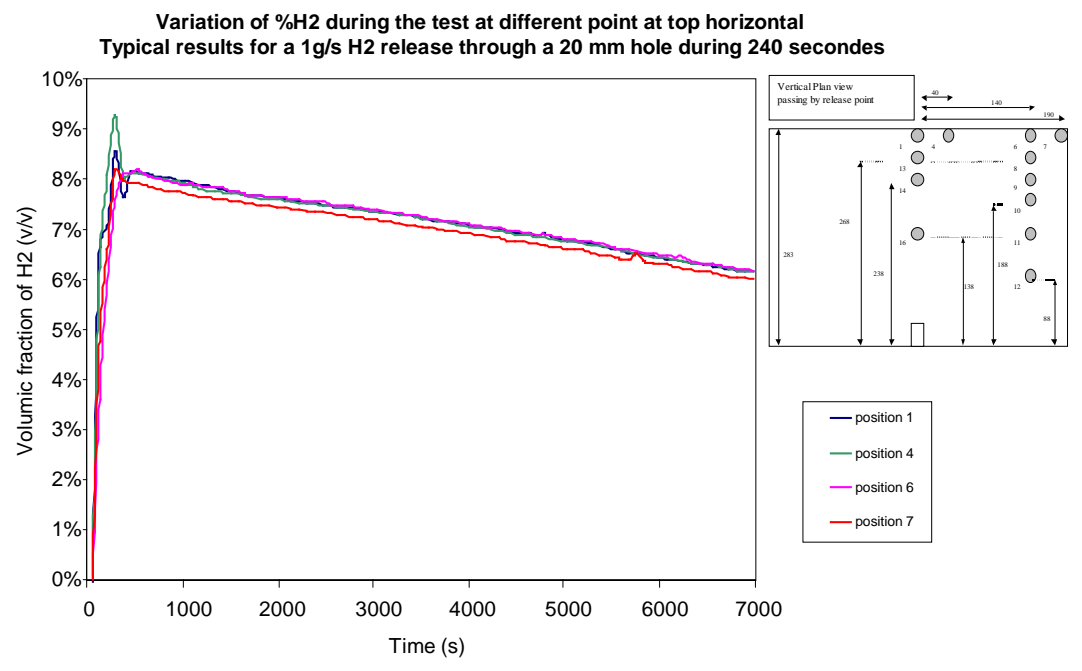

Figure 9 : variation of $\% \mathrm{H}_{2}$ for a $1 \mathrm{~g} / \mathrm{s} \mathrm{H}_{2}$ release through a $20 \mathrm{~mm}$ hole

Homogeneous concentration at a given altitude can be attributed to the residual speed of the mixture after its impingement with the ceiling coupled to the effect of mixture buoyancy. Due to the richness of the mixture, this latter remains "stuck" to the ceiling.

The peak of concentration is observed during the release phase (see Figure 10) where the concentration close to the release point (sensor 16) reaches approximately $17 \%$. A $1 \mathrm{~g} / \mathrm{s} \mathrm{H}_{2}$ release gives a jet phenomenon. Once the release phase is over, the concentration at this sampling point decreases sharply under the LFL and its value is similar with the one measured with other sensors at the same height (see Figure 8). 


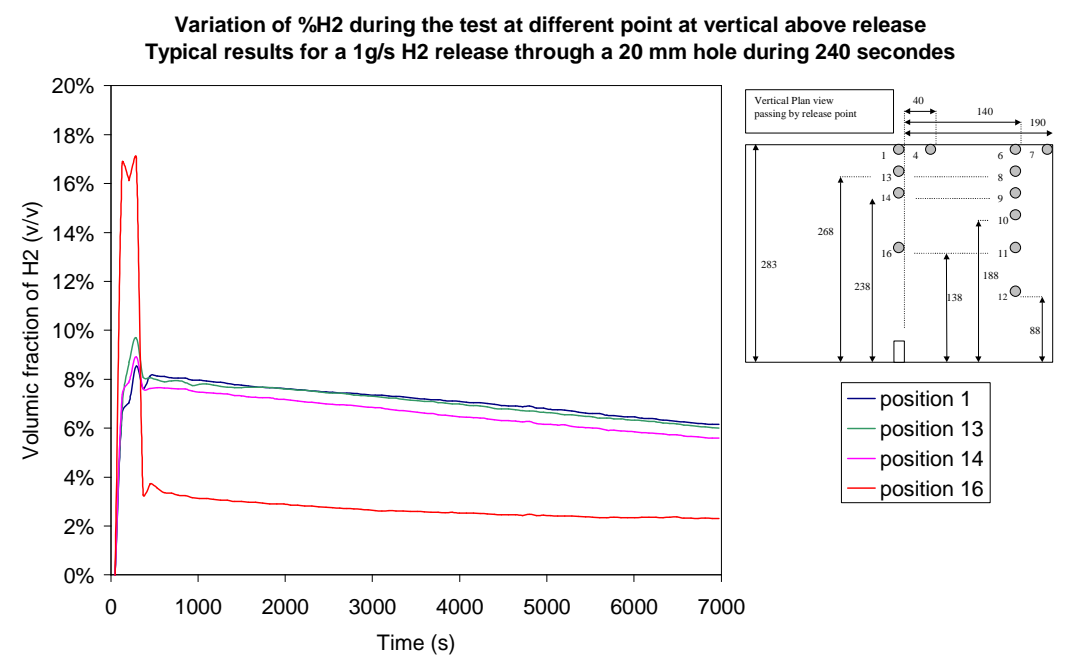

Figure 10 : variation of $\% \mathrm{H}_{2}$ for a $1 \mathrm{~g} / \mathrm{s} \mathrm{H}_{2}$ release through a $20 \mathrm{~mm}$ hole

For a $1 \mathrm{~g} / \mathrm{s} \mathrm{H}_{2}$ release through a $20 \mathrm{~mm}$ hole, an explosive layer with an approximate volume of $40 \mathrm{~m}^{3}$ volume is formed. For the smallest mass flow rate $0,2 \mathrm{~g} / \mathrm{s}$, see Figure 11, hydrogen concentration in the richest layer never reaches the hydrogen Lower Limit of Inflammability. Therefore, no explosive mixture is formed for this smallest release flow.

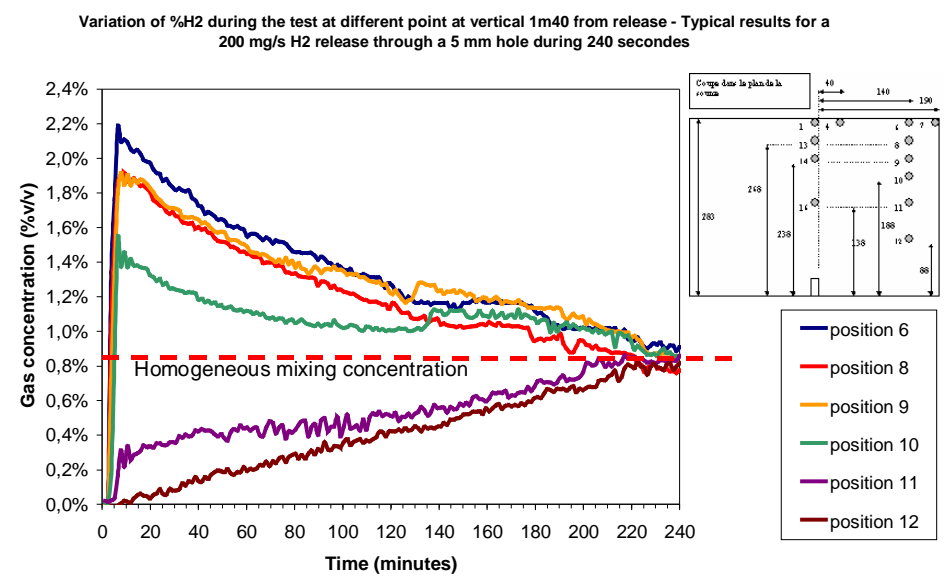

Figure 11 : variation of $\% \mathrm{H}_{2}$ for $0.2 \mathrm{~g} / \mathrm{s} \mathrm{H}_{2}$ through a $5 \mathrm{~mm}$ hole

Profiles (see Figure 12) of concentration show that hydrogen concentrations are rather homogenous in the formed layer near the ceiling. The higher the hydrogen concentration is in the top layer, the less sharp the concentration profile in the rich layer is. The concentration gradient between the top hydrogen layer and the ground increases with the release flow rate. During filling phase, the concentration in the rich layer is mainly correlated with the flow rate. Some of $0.2 \mathrm{~g} / \mathrm{s} \mathrm{H}_{2}$ releases do not behave like a turbulent jet. This seems consistent with the weakness of the Reynolds number $(\operatorname{Re} \approx$ 2000) and further studies might be necessary to investigate further this leakage phenomenon. For the higher releases $\left(1 \mathrm{~g} / \mathrm{s} \mathrm{H}_{2}\right)$ we see clearly in Figure 12 that the concentration in the upper layer increases with the orifice diameter. 


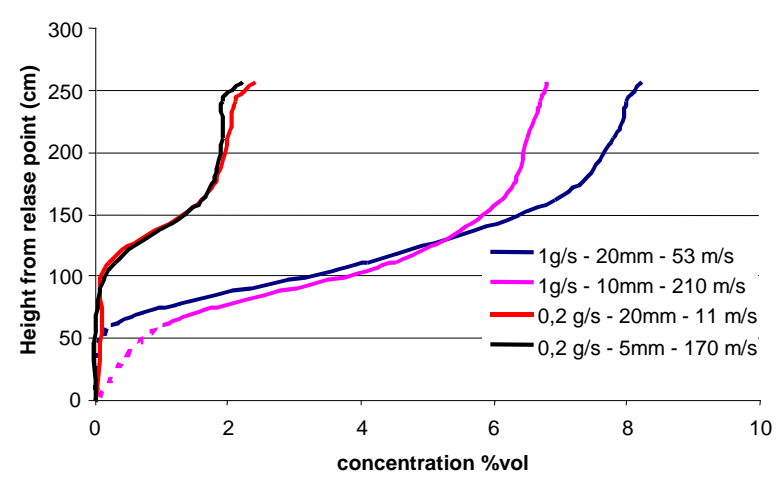

Figure 12 : concentration profile (along a vertical located at $\mathrm{x}=1.40 \mathrm{~m}$ and $\mathrm{y}=0 \mathrm{~m}$ ) for various releases after release phase

\subsection{Tightness of the chamber walls and control of small leakage}

It is very difficult to make tight such a large volume, particularly with respect to a light gas such as hydrogen. According to the studied cases, hydrogen injected into the chamber creates with the ambient air a mixture, more or less heterogeneous, whose density is lower than that of the surrounding air. As a result from this gradient of density, hydrogen can escape through tiny holes or cracks outside the chamber (see Figure 13).

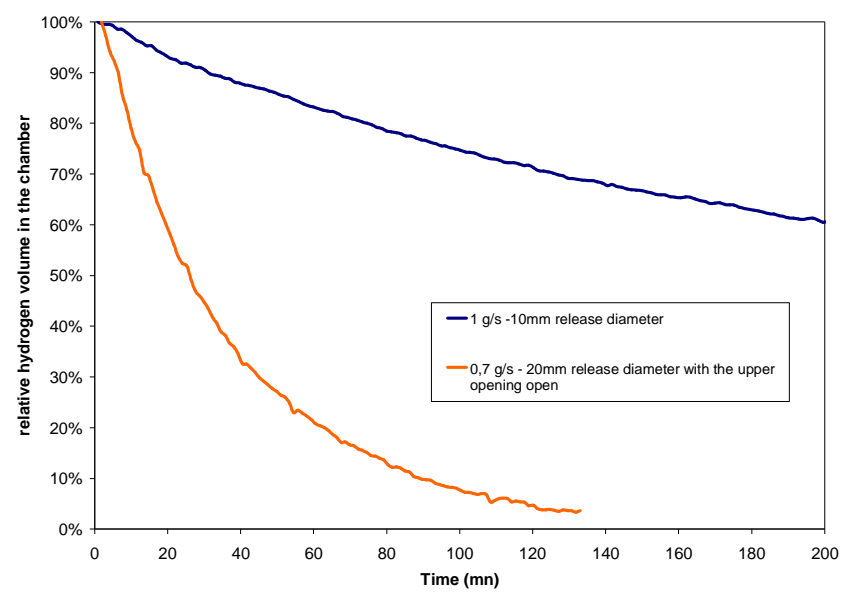

Figure 13 : decrease of hydrogen mass in the chamber due to leak and openings

The residual leakage rate is dependent on the initial quantity of hydrogen injected. After dividing the chamber into 7 layers with different thickness $(5,15,30,50,50,50$ and $88 \mathrm{~cm}$ from the ceiling to the bottom), the flow was solved in each of these layers assuming homogeneous properties in order to locate and quantify the potential leak points. The lost of hydrogen was also modelled. By using :

$\mathrm{U}=((\Delta \rho / \rho \mathrm{ext}) * \mathrm{~g} * \mathrm{~h})^{0,5}$

where U - flow velocity, $\mathrm{m} / \mathrm{s} ; \Delta \rho$ - density difference, $\mathrm{kg} / \mathrm{m}^{3} ; \mathrm{g}$ - gravitational acceleration $-\mathrm{m} / \mathrm{s}^{2} ; \mathrm{h}$ height of the mixture layer, $\mathrm{m}$; and we modelled the diffusive flow between the layers with an usual diffusion law. Comparisons between this calculation and the experiments indicated a hydrogen leak 
mainly occurring in the lower part of the chamber with an estimated equivalent leak area between 90 and $170 \mathrm{~cm}^{2}$.

With "opening 1" unclosed (top opening in front wall) assuming a 3,7 \%v/v homogeneous mixture (obtained with a 4-minute release at $1 \mathrm{~g} / \mathrm{s}$ ) our simple approach estimates that half of the injected hydrogen mass can escape from the chamber in less than 45 minutes. However, in the experimental configuration and due to vertical concentration gradient and higher hydrogen concentration at the top, the observed escape mass flow rate is higher, see Figure 13, than the one predicted with the model.

\subsection{Analysis of the video results and $\mathrm{H}_{2}$ and $\mathrm{He}$ similitude}

The visualisation of the flow gives additional information to those obtained using specific concentration measurements. The pictures below (Figure 14) show the jet production and diffusive phase respectively for a helium release case.

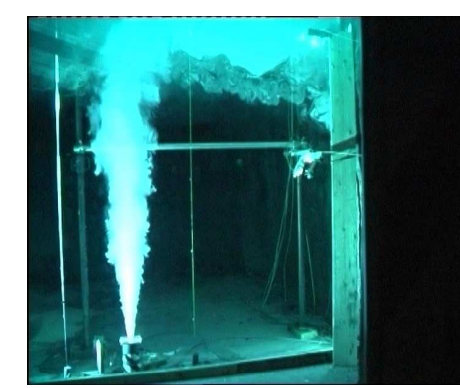

$10 \mathrm{~s}$

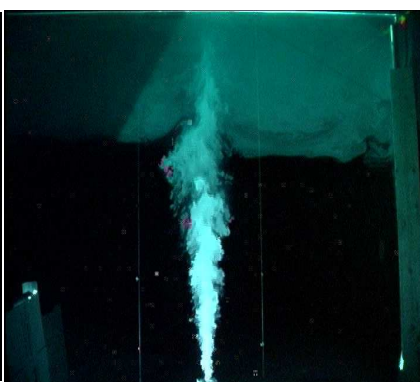

$120 \mathrm{~s}$

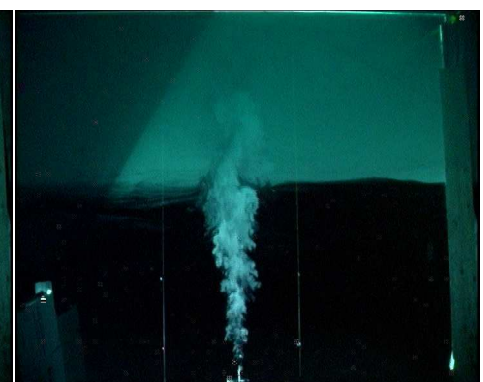

$235 \mathrm{~s}$

Figure 14 : view of helium release for a $1,84 \mathrm{~g} / \mathrm{s}$ flow rate through a $20 \mathrm{~mm}$ hole during the convection phase

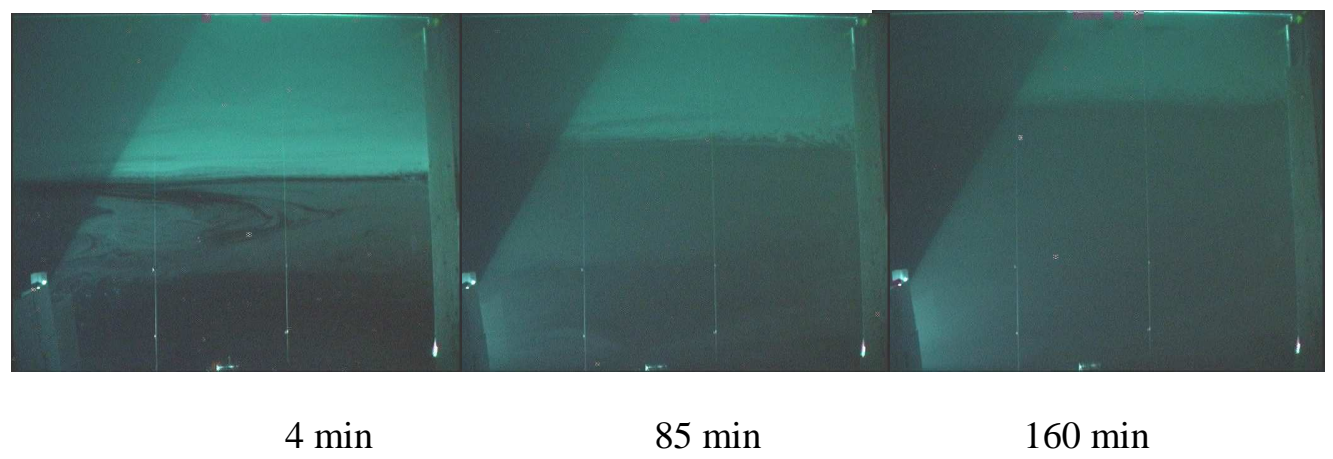

Figure 15 : view of helium release for a $1,84 \mathrm{~g} / \mathrm{s}$ flow rate through a $20 \mathrm{~mm}$ hole during the diffusive phase

Figure 14 shows the convection phase and the residual speed of the mixture after its impact at the ceiling. Views in Figure 15 confirm the long time scale of the diffusive phase. Figure 16 and Figure 17 allow us to compare the helium and hydrogen gas concentrations, along a vertical line located at $\mathrm{x}=1.4 \mathrm{~m}$ and $\mathrm{y}=0 \mathrm{~m}$, for the same volumetric flow rate (equivalent mole). The comparison indicates that the levels of concentration of helium and hydrogen in the layer near the ceiling are very close. 


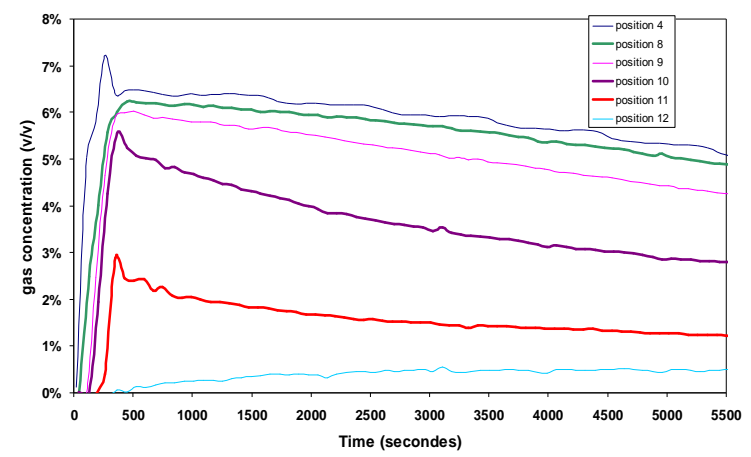

Figure 16 : variation of $\% \mathrm{He}$ for $1,84 \mathrm{~g} / \mathrm{s} \mathrm{He}$ release through a $20 \mathrm{~mm}$ hole

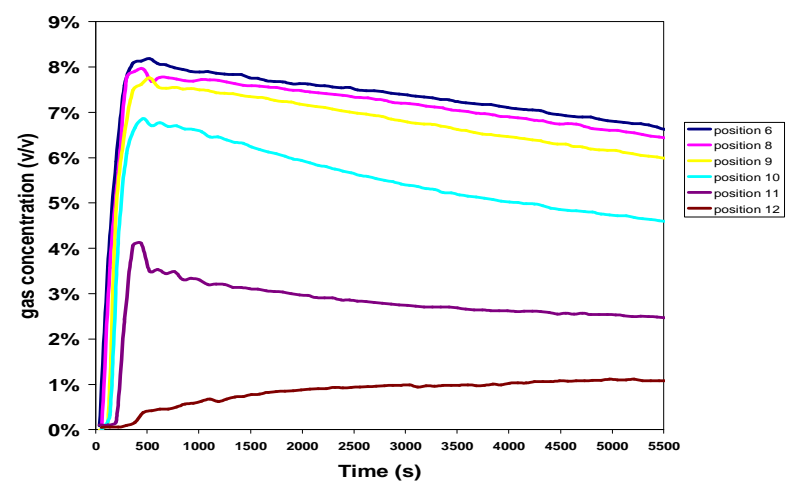

Figure 17 : variation of $\% \mathrm{H} 2$ for $1 \mathrm{~g} / \mathrm{s} \mathrm{H}_{2}$ release through a $20 \mathrm{~mm}$ hole

The concentration levels are approximately the same in the upper layer i.e. between $7 \%$ and $8 \%$ for $\mathrm{H} 2$ and between $6 \%$ and $7 \%$ for He. Helium peak concentration (at sensor position 16) is of the order of $14 \%$ (by volume) at the end of injection, this value could be compared to the hydrogen value of $17 \%$ (see Figure 10). These values are also very similar. The chamber concentration levels in $\mathrm{H}_{2}$ and $\mathrm{He}$ tests are very close as we can see with sensors 4, 6, 8, 9, 10 located in the upper-half of the chamber and with sensors 11 and 12 located in the lower-half. This result shows the good homogenisation of gas mixture in horizontal cross-section as discussed by CEA [3].

It therefore would allow us to use hydrogen-helium similitude for dispersion cases although further experiments would be necessary to draw some robust conclusions. Theses experimental cases confirm the study carried out by Swain et al. [4].

\section{CONCLUSIONS}

INERIS performed hydrogen and helium dispersion tests for a $240 \mathrm{~s}$ release time in a quiescent room for mass flow rates ranging from $0,2 \mathrm{~g} / \mathrm{s}$ to $1 \mathrm{~g} / \mathrm{s}$ and from $0,4 \mathrm{~g} / \mathrm{s}$ to $1,84 \mathrm{~g} / \mathrm{s}$ for hydrogen and helium respectively. Injection orifices varied from $5 \mathrm{~mm}$ to $20 \mathrm{~mm}$. Sensors were used to monitor the evolution of the concentrations not only during the injection phase but also a few hours later for the diffusion. 
The experimental results show that for the subsonic jet, stratification appears at the top. A diffusion phase follows this stratification and, for all the tested cases the concentration became homogeneous after four hours.

The jet characteristics influences the concentration of the rich layer and gives indications on what we can expect in terms of concentration at top level (above or below LFL) and volume of the explosive mixture if any at the end of the release.

In the studied case, a release flow of $1 \mathrm{~g} / \mathrm{s} \mathrm{H}_{2}$ generates an explosive volume corresponding approximately to half of the room. For a flow of $0.2 \mathrm{~g} / \mathrm{s}$ the hydrogen concentration never exceed the LFL.

In an experimental set up like this, hydrogen tightness is difficult to reach. However, we have been able to estimate the hydrogen loss and the equivalent leaking surface by simple calculation.

Helium tests were also carried out and results show a strong similarity with hydrogen. Moreover, video recordings during Helium tests brought complementary and very useful information.

These results will help in better predicting hydrogen dispersion in confined spaces. Another scientific paper follows soon, which will analyse further the results described here.

These experimental results can be used to assess and benchmark CFD tools capabilities and to validate dispersion models.

\section{ACKNOWLEDGEMENTS}

This experimental program has been undertaken with the financial support of the French Ministry of environment as well as the Hysafe Network of excellence. It took place in the framework of a scientific collaboration agreement between CEA and INERIS.

\section{REFERENCES}

1. Review of Existing Experimental Hydrogen-Helium Release \& Dispersion Data For Standard Benchmark Exercise Problems. HYSAFE report, 25June 2004.

2. Dagba Y., Perette L., Venetsanos A.G., Description of INERIS-test-6 experiment and requirements for corresponding blind SBEP in the framework of the InsHyde internal project, HYSAFE report, 24 October 2005.

3. Experimental results on helium release inside a full scale GARAGE set-up - CEA. HYSAFE report, 11 April 2007.

4. Swain, M.R., Filoso, P., Grilliot, E.S., Swain, M.N. (2003). Hydrogen leakage into simple geometric enclosures. Int. J. hydrogen energy, pp. 229-248. 